\title{
Habilidade oral em L2: da cognição à interação
}

\author{
Elena Ortiz Preuss \\ Universidade Federal de Goiás \\ elena.ortizp@yahoo.com.br
}

\section{Resumo}

Neste artigo, objetiva-se discutir a natureza e o desenvolvimento da fala em L2, partindo do pressuposto de que o falante é, ao mesmo tempo, processador de informação e interlocutor (Levelt, 1989). Isso significa que a habilidade oral em L2 requer o conhecimento de elementos linguísticos e padrões pragmático-discursivos das diferentes situações comunicativas, e depende do funcionamento de mecanismos cognitivos de processamento. A discussão é feita, a partir da caracterização da fala como habilidade cognitiva e social, apresentando-se mecanismos cognitivos (sistemas de memória e atenção) envolvidos na oralidade e elementos que constituem a estrutura conversacional (interlocutores e contexto). Também é feita uma reflexão sobre procedimentos de intervenção pedagógica para o desenvolvimento da fala em L2, ressaltando-se o papel da prática e da atenção seletiva.

Palavras-chave: Fala; Segunda língua; Processamento cognitivo; Interação.

\begin{abstract}
In this article we aim to discuss the nature and the development of speech in L2, assuming that the speaker is at the same time an information processor and an interlocutor (Levelt, 1989). That means that the oral skill in L2 requires the knowledge of linguistic elements and pragmatic-discursive patterns of different communicative situations, and it depends on the operation of cognitive processing mechanisms. The discussion is conducted from the characterization of speech as a cognitive and social skill, by exposing some cognitive mechanisms (memory and attention systems) involved in the oral skills and some elements that constitute the conversational structure (interlocutors and context). A reflection about pedagogical intervention procedures for the development of speech in L2 is also carried out, emphasizing the role of practice and selective attention.

Keywords: Speech; Second language; Cognitive processing; Interaction.
\end{abstract}




\section{Introdução}

A habilidade oral em segunda língua (doravante L2) ${ }^{1}$ é um aspecto da aquisição ainda pouco compreendido por pesquisadores, professores e aprendizes de L2. Muitas vezes, considera-se que o desenvolvimento dessa habilidade seja uma consequência direta da prática de conteúdos estruturais e de atividades com foco em competências ou outras habilidades linguísticas, como a compreensão leitora e auditiva, por exemplo. Sob essa perspectiva, a fala é considerada tanto como "forma" quanto como "produto" da aprendizagem de regras gramaticais, de vocabulário e de leitura, etc. Portanto, não raro, não é entendida, como uma habilidade com características próprias que demandam intervenções pedagógicas específicas (BYGATE, 2001; 2011; FORTKAMP, 2008).

Baralo (2000) argumenta que a fala não é uma habilidade isolada das outras. Entretanto, isso não significa que deva ser concebida como uma consequência dessas habilidades. Assim, práticas de leitura e audição, por exemplo, podem ser úteis para a ampliação do léxico mental e exercício da pronúncia, ambos necessários para o desenvolvimento da oralidade, mas não suficientes para transformar o aprendiz num falante altamente proficiente e que saiba agir discursivamente na L2. É preciso considerar que a fala é uma habilidade complexa, que exige processamento cognitivo anterior - e também concomitante - à sua produção e que o falante é, ao mesmo tempo, processador de informação e interlocutor, que deve adequar-se às rotinas conversacionais e ao contexto espaço-temporal, e reconhecer a intencionalidade subjacente ao ato comunicativo (LEVELT, 1989). Desse modo, a fala envolve aspectos intra e interpessoais, ao abranger o processamento mental de conhecimentos sobre o sistema linguístico (gramática, vocabulário, pronúncia, etc.) e sobre o contexto comunicativo (interlocutores, objetivo comunicativo, padrão sóciodiscursivo).

Considerando-se o falante processador e interlocutor como centro do desenvolvimento da habilidade oral, as intervenções

\footnotetext{
${ }^{1}$ Neste artigo não se distinguem os termos segunda língua (L2) e língua estrangeira (LE), e as palavras aquisição e aprendizagem são usadas indistintamente.
} 
pedagógicas com esse fim devem propiciar práticas que atendam aos aspectos do processamento da fala (mecanismos cognitivos envolvidos) e abranjam aspectos estruturais e discursivos que permeiam as ações dos interlocutores. É sob essa perspectiva que se propõe neste artigo apresentar uma breve discussão teórica sobre alguns aspectos cognitivos e pragmático-discursivos relacionados à fala em L2 e, posteriormente, algumas considerações sobre procedimentos de desenvolvimento dessa habilidade. Espera-se que os tópicos aqui discutidos possam contribuir para uma maior compreensão sobre a natureza e constituição da fala em L2 e para promover práticas de ensino da fala mais fundamentadas e eficazes.

\section{Processamento cognitivo da fala}

Um dos modelos que visam explicar o processo de produção de fala é o de Levelt (1989), o qual considera que o falante é, ao mesmo tempo, como já afirmado, processador de informação e interlocutor, pois a fala envolve complexos processos cognitivos que precedem sua articulação em diferentes situações comunicativas. Esse modelo prevê que a construção da mensagem verbal envolve processos linguísticos e conceituais através dos seguintes componentes: conceitualizador, formulador e articulador $^{2}$. A produção de fala inicia no conceitualizador que planeja a mensagem, selecionando e ordenando a informação conceitual relevante, adaptando as intenções comunicativas do falante e considerando os conhecimentos sobre o tópico, a situação comunicativa e os padrões discursivos. A partir disso, é gerada a mensagem pré-verbal que contém toda a informação necessária para transformar significado em linguagem e servirá de input para a próxima etapa do processo. No formulador, responsável pela seleção e organização formal da mensagem, faz-se a estruturação linguística, ou seja, a seleção lexical e a aplicação de regras gramaticais e fonológicas para que a mensagem seja convertida em plano fonético (fala interna). O output do formulador (plano de fala) é

\footnotetext{
${ }^{2}$ Sob essa perspectiva, a produção de fala envolve níveis de representação conceitual, lexical e fonológico, que armazenam, respectivamente, conceitos, palavras e fonemas (COSTA; et al, 2000).
} 
processado e temporariamente armazenado de maneira que possa ser realimentado pelo sistema de compreensão e a fala possa ser produzida numa velocidade normal. Em seguida, no articulador, acontece a restauração e o controle da articulação dos sons. A partir disso, o plano de fala se converte em fala real.

Nesse modelo, o sistema de compreensão de fala (através da decodificação da sequência fonética) guia o plano fonético e a fala real para monitorar o processo e detectar possíveis enganos; assim, o monitor analisa a fala produzida e, se necessário, corrige falhas. A Figura 1 ilustra esse processo de produção de fala.

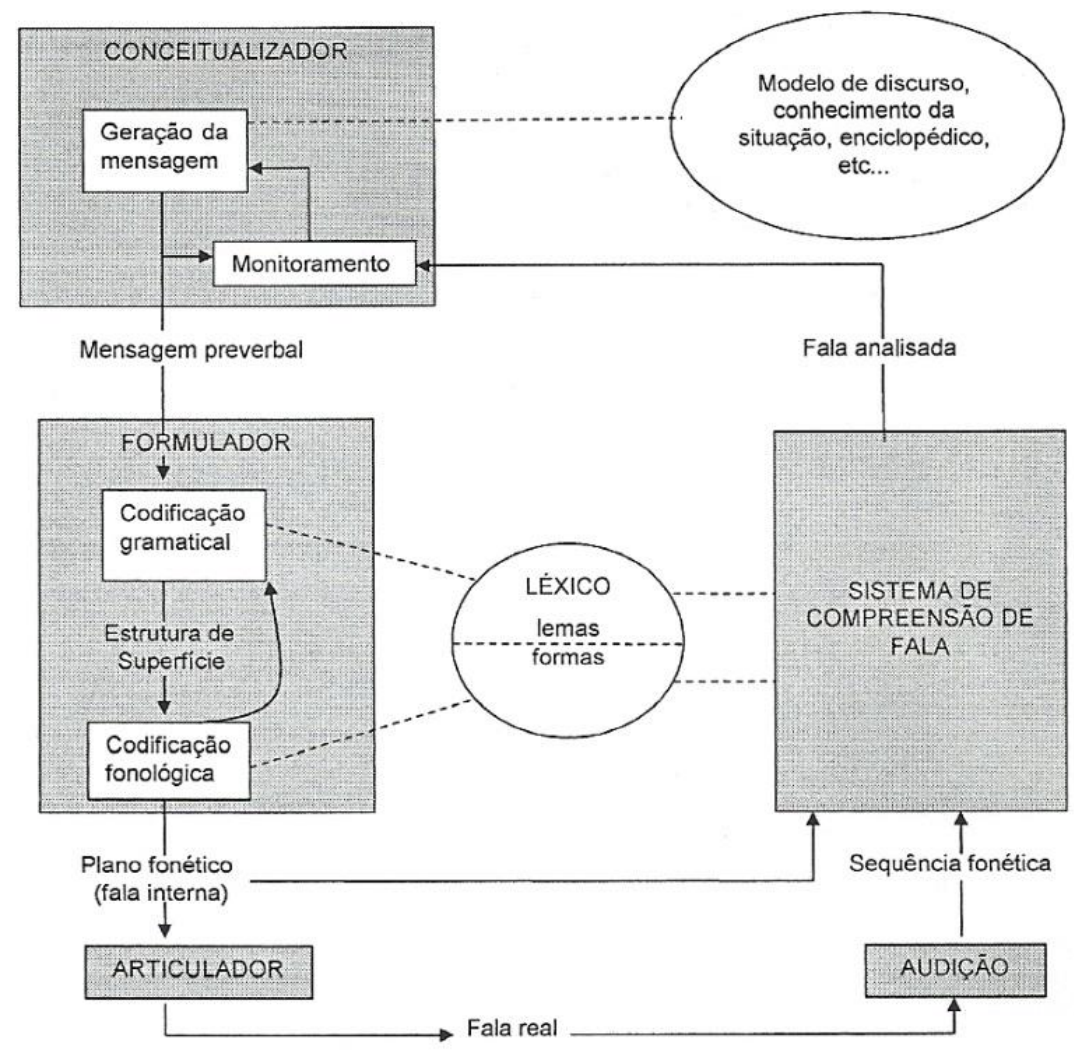

Figura 1: Modelo de produção de fala de Levelt (1989, adaptado de De Bot, 1992, p. 3). 
Conforme De Bot (1992) no modelo leveltiano, há distinção entre conhecimento declarativo (lexical e conceitual), conhecimento discursivo e conhecimento procedural (ou procedimental), o qual integra os diferentes componentes e é necessário para o processamento do conhecimento declarativo. Sob essa perspectiva, o desenvolvimento da fala envolve conhecimentos de tipo procedural/implícito ("como") e declarativo/explícito ("quê"), já que a oralidade requer que o falante conheça o sistema linguístico (saber declarativo), evidenciando isso no uso linguístico (saber procedural), via articulação sonora da comunicação (MITCHELL; MYLES, 1998).

Para Ellis (1994), o conhecimento explícito se constitui de operações conscientes, a partir do uso do conhecimento construído pelas regras da língua, recebidas em um ambiente de ensino explícito. Por outro lado, conforme o autor (idem, 1994), o conhecimento implícito é automático, sem que o aprendiz tenha consciência dos mecanismos que utiliza em sua produção linguística. Essas definições evidenciam a relação entre (a) processos automáticos e o conhecimento implícito e (b) processos controlados e o conhecimento explícito, uma vez que os primeiros não são conscientes e os últimos demandam o controle consciente.

Esses processos e conhecimentos envolvem também distintos sistemas de memória, a saber: o sistema de memória procedural e o sistema de memória declarativa. De acordo com Ullman (2001, 2004), o sistema de memória declarativa está implicado na aprendizagem, representação e uso de conhecimentos sobre fatos (semânticos) e eventos (episódicos). A memória declarativa utiliza uma memória associativa que fundamenta o conhecimento armazenado sobre palavras (sons e significados) e outras informações memorizadas, tais como morfemas e expressões idiomáticas. Por sua vez, o sistema procedural contém regras, incluindo operações e restrições para a produção e representação de palavras, frases e sentenças. Está implicado na aprendizagem do novo e no controle de hábitos e habilidades cognitivas e motoras, que são evidenciadas no desempenho.

Ainda com relação ao modelo proposto por Levelt (1989), conforme Bygate (2001), todos os processos ocorrem muito rapidamente (em milésimos de segundos) e dependem de que a articulação seja automatizada, mas a formulação e a conceitualização 
podem ser parcialmente automatizadas, uma vez que o falante precisa estar atento ao que pretende dizer. A automatização é necessária devido à capacidade limitada de atenção, que dificulta o controle consciente e simultâneo da conceitualização, da formulação e da articulação.

Segundo Ortega (2009), para as teorias de aquisição de habilidades, a aprendizagem acontece quando há a transformação gradual do desempenho, inicialmente dependente de processos controlados, passando a ser automatizado através da prática. Sob esse ponto de vista, no desenvolvimento da fala, os aprendizes de L2, primeiramente recebem explanações explícitas que, depois de exercitadas, convertem-se em habilidade de uso ou conhecimento implícito. A autora (idem, 2009) expõe que essas teorias têm sido influenciadas pelo modelo de processamento proposto por Anderson (1983), o qual prevê que o processamento da informação e a transição entre conhecimento declarativo (controlado) e procedimental (automatizado) estão relacionados à memória de trabalho, cuja capacidade também é limitada. Por isso, quanto mais procedimental torna-se o conhecimento, menos sobrecarga causa à memória de trabalho e mais fluente é a fala do aprendiz, devido ao acesso mais rápido e eficiente ao conhecimento (idem., 1983 apud MITCHELL; MYLES, 1998).

A memória de trabalho é um sistema operacional de capacidade limitada que gerencia a realidade (IZQUIERDO, 2002). Trata-se da habilidade de manter uma informação na mente e manipulá-la (DIAMOND, 2006). Ou seja, essa memória trabalha em interação com os demais sistemas mnemônicos, examinando a informação nova e comparando-a com as informações já armazenadas. Por isso, é concebida como um mecanismo de processamento e armazenamento simultâneo de informação, por um período de tempo bastante curto. Para Engle (2010), a memória de trabalho está vinculada ao mecanismo de atenção, encarregado de selecionar as informações mais relevantes para serem armazenadas durante a realização de uma tarefa.

No caso da fala em L2, o falante de nível inicial poderá ter mais dificuldade de gerenciar e executar o plano de fala, devido à pressão do tempo, à insuficiência de conhecimentos da L2 e à falta de automatização dos processos (BYGATE, 2001; FORTKAMP, 2008). 
O aprendiz de L2 precisa estar atento não só àquilo que pretende dizer, mas em como fazê-lo, com maior grau de fluência e acurácia. Falantes de L2, principalmente com menor nível de proficiência, dependem de processos mais controlados, que afetam a velocidade da fala e demandam mais atenção e capacidade de memória de trabalho.

Para Finardi e Weissheimer (2008), no modelo de Levelt (1989), a memória de trabalho armazena as representações intermediárias produzidas em cada um dos componentes, ou seja, a mensagem pré-verbal, a estrutura de superfície e o plano fonético, facilitando, assim, a continuidade do processo. Ademais, a memória de trabalho contribui com a fala, pois controla a atenção e participa na tomada de decisões para a formulação da mensagem, além de auxiliar no processamento da informação (BERGSLEITHNER, 2011). Fortkamp e Bergsleithner (2007) também afirmam que parece haver evidências de relação entre a capacidade da memória de trabalho e o desempenho oral na L2, sendo que maior capacidade de memória de trabalho corresponderia ao melhor desempenho.

Ainda com relação à memória de trabalho, deve-se ressaltar a sua relação com os aspectos afetivos e emocionais. Esse sistema operacional é afetado por estados de ânimo negativos, pois seu processamento envolve axônios de "regiões cerebrais vinculadas à regulação dos estados de ânimo, dos níveis de consciência e das emoções" (IZQUIERDO, 2002, p. 20). Em vista disso, considerandose que é na fala em L2 que muitos aprendizes parecem ter mais dificuldade de controlar suas emoções (vergonha, ansiedade, medo, etc.), pode-se supor que isso se deva aos efeitos dos aspectos emocionais no funcionamento da memória de trabalho. Em outras palavras, a ansiedade gerada pelo fato de ter que falar na L2 pode fazer com que a memória de trabalho não funcione adequadamente, ao gerenciar as informações ativadas nos diferentes componentes envolvidos no processamento da fala e nos demais sistemas de memória.

Skehan (1996), por sua vez, enfatiza a relação entre atenção e fala em L2. Segundo o autor, o desempenho depende de recursos atencionais que são limitados e abrange as seguintes dimensões: fluência, acurácia e complexidade gramatical. Skehan e Foster (2001) se baseiam no argumento de VanPatten (1990) de que os aprendizes não conseguem prestar atenção ao significado e à forma linguística, 
simultaneamente, por isso acabam priorizando o sentido. Os pesquisadores (SKEHAN; FOSTER, 2001) apresentam uma proposta na qual distinguem as dimensões do desempenho a partir da oposição forma x significado, e discutem a sua dependência de recursos atencionais. De acordo com essa proposta, a fluência se relaciona com o significado; por isso, quando o falante foca a atenção no sentido da mensagem, pode apresentar maior fluência, mas terá menos recursos atencionais dedicados à manutenção da acurácia e da complexidade gramatical. Por sua vez, acurácia e complexidade se relacionam com a forma; por isso, o foco de atenção na acurácia pode prejudicar a fluência e provocar uma fala com estruturas linguísticas mais simples (menos orações subordinadas, por exemplo), ao passo que a atenção focada na complexidade gramatical pode prejudicar a fluência e a acurácia (idem, 2001). A figura 2 ilustra essa proposta de dimensões do desempenho.

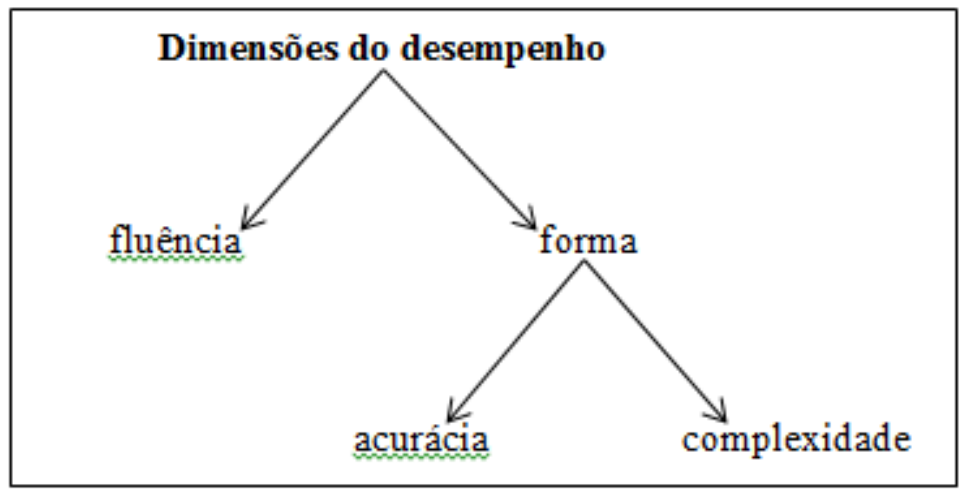

Figura 2: Proposta de dimensões do desempenho de Skehan e Foster (2001, p. 190). ${ }^{3}$

Conforme exposto até aqui, o processamento da fala envolve mecanismos cognitivos de memória e atenção que operam de forma diferenciada com relação à forma e ao significado linguístico, o qual pode envolver aspectos pragmático-discursivos inerentes aos distintos contextos comunicativos e que serão discutidos na seguinte seção.

${ }^{3}$ Quadro traduzido pela autora deste artigo. 


\section{Contexto pragmático-discursivo e habilidade oral}

Biologicamente, a fala é o produto da transformação dos conceitos ativados em padrões sonoros que são articulados pelo aparelho fonador. Para isso, é necessária a ativação lexical adequada, a estruturação formal da mensagem e a restauração dos segmentos fonológicos (COSTA et al, 2000). Entretanto, a habilidade oral não pode ser compreendida somente como a produção da cadeia sonora, a partir de fonemas, pois a construção de sentido, muitas vezes, não decorre da linearidade do enunciado, mas sim da sua relação contextual. Martín Peris (1996) ressalta, também, que a transmissão de mensagens orais é facilitada e agilizada pela conjunção de elementos linguísticos (fonético-fonológicos, morfológicos, sintáticos, etc.), paralinguísticos (gestos, movimentos corporais, traços da voz, entre outros tipos de comunicação não verbal) e extralinguísticos (tema, objetivo e demais aspectos que constituem a situação comunicativa).

Portanto, a fala é amplamente dependente do contexto, o qual contempla as circunstâncias espaço-temporais e fatores como relação entre os interlocutores e entorno social ou cultural. Conforme Baralo (2000), a forma como o jogo interlocutivo se produz tem motivado vários estudos, tendo em vista que depende de variáveis culturais e sociais, das intenções dos falantes e sua dimensão cognitiva. A simetria das relações existentes entre os interlocutores, por exemplo, afeta a liberdade dos falantes para iniciar ou desenvolver o tópico, pedir esclarecimentos ou concluir a interação. Em outras palavras, nas diferentes situações comunicativas, nem todos os falantes têm igual direito à fala, isto é, alguns interlocutores têm mais controle sobre o processo conversacional que outros, como no caso das interações entre médico e paciente, entre professor e aluno, entre patrão e funcionário, etc. (BYGATE, 2001, 2011; MARTÍN PERIS, 1996).

Conforme Rabanal García (2000), as conversas face a face são variadas (formais/informais, públicas/privadas) e, consequentemente, as regras e a estrutura conversacional se alteram, interferindo nas formas de agir dos falantes e seus usos linguísticos que devem se adequar à situação comunicativa. Ademais, a oralidade é constituída de mecanismos e normas conhecidas, muitas vezes inconscientemente, pelos falantes, e os enunciados são também produto da postura pessoal 
dos falantes, das suas escolhas linguísticas, e das estratégias de polidez e de proteção da face que utilizam.

Rabanal García (2000) afirma que a interação oral é regida por dois princípios: o sistema de turnos e a cooperação entre os interlocutores. As estratégias interativas, centradas nos turnos, enfocam as formas de tomar, manter e/ou ceder o turno, como, por exemplo, com o uso de marcadores discursivos, pausas. Por sua vez, a cooperação facilita os intercâmbios comunicativos, pois os interlocutores reconhecem seus propósitos comuns. Em outras palavras, a interação oral ocorre por meio de atos de fala, que se concretizam em turnos alternados entre os interlocutores. Nas distintas etapas de turnos ocorrem intercâmbios comunicativos e negociações de significado, conforme princípios que regem a conversação (cortesia, cooperação e implicaturas conversacionais) (idem, 2000). Baralo (2000) argumenta que a comunicação visa ao intercâmbio de informações e que a expressão oral ocorre dentro de um contexto compartilhado, numa situação de negociação de significados que requer a participação ativa de emissor e de receptor; isto é, envolve interação e comunicação bidirecional.

Além disso, para cumprir os propósitos comunicativos, a fala também permite referências implícitas, através da comunicação não verbal, por meio de gestos e/ou movimentos corporais, já que as interações são fisicamente situadas. Desse modo, os falantes podem se ver e se referir ao contexto físico e usar sinais físicos para chamar a atenção, mostrar intenções e atitudes em relação ao que está sendo dito. Mesmo no caso de interação oral a distância (conversa telefônica, por exemplo), em que os falantes não se veem e não usam movimentos corporais, as referências implícitas podem ocorrer através de pausas, silêncios, e mudanças na entonação e no ritmo (BYGATE, 2001, 2011; MARTÍN PERIS, 1996).

A fala também se caracteriza por ser uma habilidade tipicamente recíproca, imediata e espontânea. Várias pessoas podem participar numa mesma interação, mas cada falante dispõe de pouquíssimo tempo (milésimos de segundo) para pensar e formular o que vai dizer, e, simultaneamente, precisa reagir adequadamente à fala de seus interlocutores. Assim, o desenvolvimento das interações comunicativas é imprevisível e o discurso oral se produz em cooperação, através do feedback recíproco entre os interlocutores. 
Ademais, as condições de processamento on-line podem gerar produções linguísticas fragmentadas, com repetições lexicais e frasais, com mais frases incompletas ou interrompidas e frases formulaicas, no mesmo fragmento de discurso. Em suma, dentre os recursos expressivos próprios da oralidade, pode-se destacar: entonação, ritmo, pausas, silêncios, repetições, uso de expressões coloquiais e idiomáticas, uso de estratégias de comunicação, etc. (BYGATE, 2001; MARTÍN PERIS, 1996; PINILLA GÓMEZ, 2005).

De acordo com Silva, Andrade e Ostermann (2009), a interação oral é sequencial, já que as frases estabelecem relação com o que já foi dito pelos outros interlocutores, através de mecanismos interacionais, como pares adjacentes, organização de preferência, da tomada de turnos e do reparo. Com relação aos pares adjacentes, como pergunta/resposta, por exemplo, os autores (idem, 2009) argumentam que as falas são pareadas porque o que é dito num turno afeta o desenvolvimento do turno seguinte. Isto é, uma pergunta requer uma resposta; um convite requer o aceite ou recusa. Mas a imprevisibilidade do desenvolvimento da interação real se mantém, já que não é possível saber antecipadamente se a resposta será positiva ou negativa, nem se o convite será aceito ou recusado. A organização de preferência se refere ao fato de que as ações provocadas por um par adjacente não são equivalentes; isto é, a estrutura interacional para dar uma resposta positiva é diferente da estrutura para dar uma resposta negativa (pode haver diferenças na ênfase comunicativa, na necessidade de justificativa e na ocorrência de hesitações na fala). A organização da tomada de turnos é necessária, porque a interação oral se constitui de turnos que são alternados e negociados entre os interlocutores, dependendo das suas relações sociais. Por sua vez, a organização do reparo refere-se ao fato de que é frequente a ocorrência de problemas/falhas de comunicação que prejudicam o fluxo conversacional e exigem algum tipo de reparo, o qual pode ser iniciado tanto pelo falante quanto pelo ouvinte.

Rabanal García (2000) destaca também o papel da análise pragmática da interação oral. Segundo a autora, a pragmática enfoca os princípios que guiam a interpretação de enunciados, considerando os interlocutores, a situação comunicativa e o contexto linguístico. De acordo com Kasper e DuFon (2000), a pragmática estuda o uso da língua a partir da perspectiva dos falantes e distingue duas dimensões: 
a pragmalinguística, que é a forma como a estrutura linguística é usada para produzir significado pragmático; e a sociopragmática, que se refere às restriçõos sociais e culturais de uso da língua. A forma escolhida por um falante para dizer algo (pragmalinguística) é influenciada tanto pelas suas relações com o ouvinte (posições sociais, familiaridade), quanto pela gravidade do que é expressono ato de fala (sociopragmática). Nessa perspectiva, Pinilla Gómez (2000) argumenta que os marcadores discursivos também devem ser analisados sob o enfoque pragmático, pois seu significado é dado pelo contexto e pela intenção do falante e é conhecido, muitas vezes, por inferência, já que a comunicação não se reduz a processos de de/codificação linguística.

Kasper e DuFon (2000) afirmam, ainda, que estudos sobre a pragmática da interlíngua têm evidenciado a ocorrência de transferência pragmática da L1 para a L2, principalmente, no contexto formal de ensino, cujas oportunidades de receber insumo e de interagir significativamente são reduzidas. Além disso, argumentam que a informação cultural e pragmática é transmitida de forma implícita, via interação entre professor e aprendiz, mas talvez sejam necessários procedimentos mais explícitos para que essa aprendizagem seja eficaz. Ainda, conforme as autoras (idem, 2000, p. 251), é preciso compreender melhor como acontece o desenvolvimento da pragmática com relação aos aspectos linguístico-cognitivos ${ }^{4}$ (a relação entre aprendizagem de gramática e pragmática e o papel "do processamento cognitivo e interativo no desenvolvimento pragmático") e sociocultural ("os valores culturais, a subjetividade do aprendiz e a aprendizagem da pragmática").

Portanto, assim como pode haver interferências entre as línguas no que se refere aos seus elementos linguísticos, pode haver a transferência de padrões interacionais da L1para a fala em L2, envolvendo os elementos paralinguísticos e extralinguísticos. Mas quando há diferenças nesses padrões entre as duas línguas, o êxito comunicativo fica comprometido. Alcón Soler (2000, p. 272) ressalta, ainda, que é preciso analisar se as interações orais promovidas com o propósito de desenvolver a competência discursiva oral têm efeito nos conhecimentos declarativo e procedimental. Sob essa perspectiva,

\footnotetext{
${ }^{4}$ As autoras discutem o papel do noticing (SCHMIDT, 2001) e do foco na forma (DOUGHTY; WILLIAMS, 1998) nesse processo.
} 
promover o ensino da fala, somente a partir de atividades, envolvendo diferentes situações comunicativas, em que o aprendiz deve interagir significativamente, pode não ser suficiente para que ele consiga inferir e apreender as regras pragmático-discursivas que regem a conversação.

$\mathrm{Na}$ próxima seção, discute-se com mais profundidade procedimentos para o desenvolvimento da fala em ambientes formais de ensino.

\section{Desenvolvimento da habilidade oral}

A fala é uma das principais formas de comunicação humana e possui, pelo menos, duas funções básicas: a transacional, que é a transmissão de informações, e a interacional, que se refere à manutenção de relações sociais (GIOVANNINI et al. 1996; VÁZQUEZ, 2000). Trata-se de uma habilidade que se manifesta através de atividades linguísticas básicas de produção, expressão e interação oral. A produção oral se refere às atividades com foco na articulação sonora (fonética); a expressão oral relaciona-se mais com a função transacional da fala, ou seja, com situações de transmissão de informação; e a interação oral se relaciona com a função interacional, abrangendo situações de intercâmbio conversacional. Pinilla Gómez (2005) refere-se à expressão oral numa concepção ampla, abrangendo tanto contextos em que só o falante produz discurso, quanto contextos em que ele atua alternativamente como falante e ouvinte, havendo, portanto, interação. Entretanto, é preciso ressaltar que, numa mesma situação comunicativa, os três tipos de atividades podem aparecer. Por exemplo, numa conversa telefônica, ocorre a produção sonora dos enunciados, a transmissão de informações (expressão) e a manutenção de relação (interação) (PINILLA GÓMEZ, 2005; GIOVANNINI et al., 1996).

De acordo com Giovanniniet al (1996), o desenvolvimento da habilidade oral deve abranger conhecimentos e capacidade de gerenciamento dessa habilidade. Segundo o autor, a habilidade oral éconstituída de micro-habilidades capacitadoras, integrativas e de atuação. As micro-habilidades capacitadoras referem-se ao conhecimento sobre registros formais/informais e sobre elementos segmentais, suprassegmentais (articulação dos sons) e discursivos 
(coesão e coerência). As integrativas referem-se ao conhecimento de aspectos de tomada de turnos e de comunicação interativa e transacional. Finalmente as micro-habilidades de atuação referem-se ao agir, usando conhecimentos sobre a produção, controle de interação, mudança de código e integração de informação.

Nessa perspectiva, os exercícios orais podem contemplar as diferentes atividades linguísticas (produção, exposição e interação) e as diferentes funções da fala, através de gêneros distintos como, por exemplo, exposição oral (função transacional), debate (função interacional) e trava-línguas (produção). Mas é necessário que sejam contempladas também atividades de prática oral que permitam o uso de recursos típicos da oralidade, como repetições, anacolutos sintáticos, reestruturação frasal, elipses, uso de dêiticos, estratégias de comunicação, etc. Segundo Giovannini et al (1996), muitas vezes, alguns desses recursos comuns na L1 são, equivocamente, considerados como erro ou insuficiência de conhecimento na L2.

Pinilla Gómez (2005), por sua vez, defende o desenvolvimento integrado das habilidades linguísticas, tendo em vista que na comunicação cotidiana as habilidades aparecem sempre integradas. Por exemplo, numa conversa informal aparecem, simultaneamente, a fala e a audição, e numa conferência podem aparecer a leitura, a audição e a fala. A autora (idem, 2005, p. 889) argumenta que o desenvolvimento da habilidade oral deve ser feito em fases. Inicialmente, na fase de assimilação (relacionada com a compreensão auditiva), faz-se a apresentação linguística e prática controlada da produção oral, com foco nos aspectos formais, através de atividades de repetição e de memorização de pequenos diálogos, etc. Posteriormente, na fase de criação, promove-se a produção dirigida pelo professor e a produção livre, através de entrevistas, simulações, etc.

A autora (idem, 2005) também ressalta a necessidade de se minimizar efeitos de características pessoais, como medo, ansiedade, timidez, entre outros, que podem dificultar o desenvolvimento da fala. Pinilla Gómez (2005), então, sugere fases de desenvolvimento da expressão oral que abrangem: pré-atividade; exposição de objetivos e procedimentos; desenvolvimento da atividade; avaliação; e pósatividade.

Para Bygate (2001) e Martín Peris (1996), aspectos como a familiaridade com o interlocutor, o conteúdo e o tipo de ato de fala 
podem afetar a produção do falante de L2, podendo gerar muita pressão sobre ele. $\mathrm{O}$ autor argumenta que além de se encorajar o uso de estratégias comunicativas, é necessário promover a prática de diferentes tipos de interações e de padrões de discurso, bem como a fala improvisada sobre algum conteúdo familiar. Ele sugere a abordagem por tarefas, por possibilitar a prática de repetição e o foco atencional diferenciado entre fluência, acurácia e complexidade. Essa proposta, também apresentada por Skehan (2001), está em consonância com a hipótese do noticing de Schmidt (2001) e a proposta de instrução de processamento de VanPatten (1990), porque leva em consideração a capacidade limitada de atenção e de processamento linguístico. Para Schmidt (2001, p. 30-31), a aprendizagem depende do foco atencional; ou seja, para adquirir fonologia, o aprendiz deve prestar atenção aos sons do insumo da língua-alvo; da mesma forma, para adquirir pragmática, ele deve prestar atenção aos enunciados e suas relações sóciocontextuais, e assim por diante.

$\mathrm{O}$ direcionamento atencional dos aprendizes tem norteado intervenções pedagógicas com o foco na forma, através de tarefas de despertar a consciência do aprendiz (consciousness-raising tasks), direcionando sua atenção a determinadas estruturas linguísticas presentes no insumo (Ellis, 1998). Conforme Ellis (2005) a instrução com foco na forma, pode ser realizada através de instrução explícita (indutiva ou dedutiva), instrução implícita (input [não] realçado), input estruturado, produção prática (controladas, livres e funcionais) e feedback corretivo (implícito ou explícito).

Em vista do exposto, no desenvolvimento da fala é preciso levar em consideração duas constatações. A primeira relaciona=se ao fato de que a fala é uma habilidade procedimental e, portanto, seu desenvolvimento requer diferentes oportunidades de prática para que os processos controlados se automatizem. A segunda refere-se ao fato de que há competição entre forma e significado no âmbito do conhecimento declarativo, e entre as três dimensões do desempenho (acurácia, fluência e complexidade), principalmente, em estágios iniciais de aquisição. Dessa forma, as intervenções pedagógicas precisam considerar a importância de focalizar a atenção aos elementos (linguísticos, paralinguísticos e extralinguísticos) e de oferecer diferentes oportunidades de prática (controladas, semi-controladas e livres), através de atividades de produção, expressão e/ou interação 
oral. Finalmente, ressalta-se que o desenvolvimento da fala em L2 pode ser realizado de diversas maneiras, mas é preciso que sejam contempladas as especificidades dessa habilidade, no que se refere à dependência da prática e de que a atenção seja especificamente focada , ora em determinados aspectos formais, ora no significado.

\section{Considerações finais}

Partindo do pressuposto de que, para refletir sobre os procedimentos pedagógicos para o ensino e desenvolvimento da fala em L2, é preciso levar em consideração tanto os aspectos cognitivos envolvidos no processamento da fala, quanto os elementos linguísticos, extralinguísticos e paralinguísticos que a constituem, neste artigo, objetivou-se discutir teoricamente alguns aspectos cognitivos e pragmático-discursivos envolvidos na fala em L2, e refletir sobre procedimentos de ensino dessa habilidade.

No âmbito cognitivo, observou-se que a fala é uma habilidade procedural que requer prática para a automatização de procedimentos e depende de recursos atencionais e distintos sistemas de memória. No âmbito pragmático-discursivo, observou-se que a fala desenvolve-se em atividades de produção, expressão e interação, e que depende do contexto (linguístico, situação comunicativa, interlocutores) para a produção de sentido. Sob essa perspectiva, além do conhecimento sistêmico, o falante precisa saber usá-lo adequadamente; isto é, saber verbos no pretérito, por exemplo, não significa saber relatar fatos no passado. Os exercícios orais, portanto, não devem ser reduzidos à mera prática de conteúdos estruturais; pelo contrário, devem promover o efetivo exercício da língua em uso.

Do exposto até aqui, é preciso salientar, portanto, que o desenvolvimento da habilidade oral requer considerar o processamento e a atuação do falante. Para isso, não se defende uma única abordagem de ensino. Apenas se expuseram alguns aspectos a serem considerados no desenvolvimento da fala, como a necessidade de diferentes oportunidades de prática (controlada, semi-controlada e livre, envolvendo conteúdos linguísticos, discursivos e pragmáticos) e de se priorizar a atenção seletiva à forma ou ao significado. Acredita-se que vários métodos ou abordagens permitem tratar adequadamente a 
habilidade oral, na medida em que enfatizem a produção do significado, possibilitem o direcionamento dos recursos atencionais do aprendiz e lhes ofereçam oportunidades de prática. Espera-se que essa discussão contribua para uma maior compreensão sobre a fala em L2, gerando, assim práticas de ensino eficazes e melhor fundamentadas.

\section{Referências}

ALCÓN SOLER, Eva. Desarrollo de la competencia discursiva oral en el aula de lenguas extranjeras: perspectivas metodológicas y de investigación. In: MUÑOZ, Carmen. (Ed.) Segundas lenguas: adquisición en el aula. Barcelona: Editorial Ariel, S.A. 2000. p. 259276.

BARALO, Marta. El desarrollo de la expresión oral en el aula de E/LE. Carabela, Madrid, n. 47, p. 5-36, 2000.

BERGSLEITHNER, Joara. M. Atenção e memória de trabalho na produção oral em L2. In: BERGSLEITHNER, Joara. M.; WEISSHEIMER, Janaína.; MOTA, Mailce. B. (Orgs.) Produção oral em LE: múltiplas perspectivas. Campinas: Pontes, 2011, p. 21-46.

BYGATE, Martin. Teaching and testing speaking. In: LONG, Michael H.; DOUGHTY, Catherine J. (Eds.) The handbook of language teaching. Oxford: Blackwell Publishing Ltd, 2011. p. 412-440.

. Speaking. In: CARTER, Ronald; NUNAN, David. (Eds.). The Cambridge guide to teaching English to speakers of other languages. Cambridge: Cambridge University Press, 2001. p. 14-20.

CELCE-MURCIA, Marianne; BRINTON, Donna M.; GOODWIN, Janet M. Teaching pronunciation: a course book and reference guide. 2 ed. Cambridge: Cambridge University Press, 2010, p. 1-49.

COSTA, Albert.; COLOMÉ, Àngels; CARAMAZZA, Alfonso. Lexical access in speech production: the bilingual case. Psicológica, v, 21, n. 2, p. 403-437, 2000. 
DE BOT, Kees. A bilingual production model: Levelt's speaking' model adapted. Applied Linguistics, v. 13, n. 1, p. 1-24, 1992.

DIAMOND, Adele. The early development of executive functions. In: BIALYSTOK, Ellen; CRAIK, Fergus. I. M. (Eds.) Lifespan cognition: mechanisms of change. Oxford: New York, 2006.

DOUGHTY, Catherine; WILLIAMS, Jessica. (Eds.). Focus on form in classroom second aanguage acquisition. Cambridge, MA: Cambridge University Press, 1998.

ELLIS, Nick. Implicit and explicit language learning: an overview. In: ELLIs, Nick (Ed.). Implicit and explicit learning of languages. San Diego, CA: Academic Press, 1994. p.1-32.

ELLIS, Rod. Instructed second language acquisition: a literature review. Auckland: Ministery of Education, New Zealand, 2005. Disponível em: http://www.atriumlinguarum.org/contenido/instructedsecond-language.pdf. Acesso em: 14 mar. 2012.

Teaching and research: options in grammar teaching. TESOL Quarterly, v. 32, n. 1, p. 39-60, 1998.

ENGLE, Randall. W. Role of working-memory capacity in cognitive control. Current Anthropology, v. 51, n. 1, p. 17 - 26, 2010.

FINARDI, Kyria; WEISSHEIMER, Janaína. On the relationship between working memory capacity and L2 speech development. Signótica,v. 20, n. 2, p. 367-391, 2008.

FORTKAMP, Mailce B. Produção oral e aquisição de L2: cognição e ensino. In: MATZENAUER, Carmen L. B. et al. (Org.) Estudos da Linguagem: VII Círculo de Estudos Linguíísticos do Sul. Pelotas: Educat, 2008. p. 223-234. 
; BERGSLEITHNER, Joara M. Relationship among individual differences in working memory capacity, noticing, and L2 speech production. Signo, v. 32, n. 52, p.40-53, 2007.

GIOVANNINI, Arno; MARTÍN PERIS, Ernesto; RODRÍGUEZ, María; SIMÓN, Terencio. Profesor en acción 2: áreas de trabajo. Madrid: Edelsa, 1996.

. Profesor en acción 3: destrezas. Madrid: Edelsa, 1999.

IZQUIERDO, Ivan. Memória. Porto Alegre: Artmed, 2002.

KASPER, Gabriele; DuFON, Margaret A. La pragmática de la interlengua desde una perspectiva evolutiva. In: MUÑOZ, Carmen. (Ed.) Segundas lenguas: adquisición en el aula. Barcelona: Editorial Ariel, S.A. 2000. p. 231-257.

LEVELT, Willem. J. M. Speaking: from intention to articulation. Cambridge, MA: Bradford/MIT Press, 1989.

MARTÍN PERIS, Ernesto. Propuestas de trabajo de la expresión escrita. Monográficos MarcoELE, n. 8, 2009. Disponível em: <http://marcoele.com/descargas/expolingua1993_martin2.pdf >. Acesso em: 25 set. 2014.

MITCHELL, Rosamond; MYLES, Florence. Second language learning theories. London: Arnold, 1998.

ORTEGA, Lourdes. Understanding second language acquisition. New York, Routledge, 2013.

PINILLA GÓMEZ, Raquel. La expresión oral. In: SÁNCHEZ LOBATO, Jesús; SANTOS GARGALLO, Isabel. Vademécum: para la formación de profesores. Madrid: SGEL, 2005. p. 879-898.

RABANAL GARCÍA, María P. El español coloquial de la conversación: estudio de algunos marcadores. In: DOMINGUES, 
Larrañaga. (Ed.). Forma: formación de formadores. Serie Cuadernos de didáctica ELE. Madrid: SGEL, v. 1, 2001. p. 111-123.

SCHMIDT, Richard. Attention. In: ROBINSON, Peter. (Ed.) Cognition and second language instruction. Cambridge: Cambridge University Press, 2001. p.3-32.

SKEHAN, Peter. FOSTER, Pauline. Cognition and tasks. In: ROBINSON, Peter. (Ed.) Cognition and second language instruction. Cambridge: Cambridge University Press, 2001. p. 183-205.

SKEHAN, Peter. A framework for the implementation of task-based instruction. Applied Linguistics, v.17, n.1, p.38-62, 1996.

SILVA, Caroline R. et al. Análise da conversa: uma breve introdução. ReVEL, v. 7, n. 13, p. 1-21, 2009. Disponível em:

$<$ http://www.revel.inf.br/files/artigos/revel_13_analise_da_conversa.p df $>$. Acesso em 10 out. 2014.

ULLMAN, Michael T. Contributions of memory circuits to language: the declarative/procedural model. Cognition, v. 92, p. 231-270, 2004.

. The neural basis of lexicon and grammar in first and second language: the declarative/procedural model.Bilingualism: Language and Cognition, v. 4, n. 1, p.105-122, 2001.

VÁZQUEZ, Graciela.: La destreza oral. Madrid: Edelsa, 2000.

Submetido em: 29/10/2014 Aceito em: 01/05/2015

Title: Oral skill in L2: from cognition to interaction 